\title{
Educação Ambiental Como Forma De Transformação Social No Ensino Fundamental II
}

\author{
Educación Ambiental Como Forma De Transformación Social En La Enseñanza \\ Fundamental II
}

\section{Elvis Castro Reis ${ }^{1}$}

Resumo: Este artigo apresenta uma visão crítica sobre o ensino da Educação Ambiental - EA pelos docentes que ministram aulas no ensino fundamental II na rede municipal de ensino de Sento Sé/Ba. Buscando analisar como e em quais momentos as temáticas ambientais estão sendo utilizadas por esses professores e gestores na sua prática pedagógica. Visando identificar se os mesmos conhecem a legislação com relação ao processo de inclusão do eixo da EA na educação básica, e se estão sendo abordadas nas escolas. Conhecer também o grau de familiaridade dos docentes e gestores frentes a temáticas, verificando a frequência e qualidade da sua utilização em sala de aula e se abrange alem das paredes da escola atingindo também a sociedade. Neste contexto, a pesquisa trata-se de um estudo de abordagem qualitativa com enfoque descritivo, que lança mão de questionário aplicada para uma amostra de onze docentes e três gestores representantes da Escola Núcleo Dois de Julho quanto a importância do ensino de educação ambiental como forma de transformação social pelos docentes e gestores nessa escola, visto que muitos docentes não possuem a consciência de que a EA possibilita modificar intensamente as relações do homem e meio ambiente permitindo uma interatividade e mutualidade, assim sendo, a escola não pode ficar excluída desta realidade, devendo os docentes e gestores propiciarem uma maior frequência do uso de temáticas voltadas para a EA.

Palavras Chave: Docentes; Educação Ambiental; Socioambiental

Resumen: Este artículo presenta una visión crítica sobre la enseñanza de la Educación Ambiental - EA por los docentes que ministran clases en la enseñanza fundamental II en la red municipal de enseñanza de Sento Sé / Ba. Buscando analizar cómo y en qué momento las

\footnotetext{
${ }^{1}$ Universidad Autónoma de Asunción - Paraguay. Magister em Ciencias de la Educación. Email: elvis.castroreis83@gmail.com
} 
temáticas ambientales están siendo utilizadas por esos profesores y gestores en su práctica pedagógica. Con el fin de identificar si los mismos conocen la legislación con relación al proceso de inclusión del eje de la EA en la educación básica, y se están abordando en las escuelas. Conocer también el grado de familiaridad de los docentes y gestores frente a temáticas, verificando la frecuencia y calidad de su utilización en el aula y se abarca además de las paredes de la escuela alcanzando también a la sociedad. En este contexto, la investigación se trata de un estudio de abordaje cualitativo con enfoque descriptivo, que lanza mano de cuestionario aplicada para una muestra de once docentes y tres gestores representantes de la Escuela Núcleo Dos de Julio en cuanto a la importância de la enseñanza de educación ambiental como forma de transformación social por los docentes y gestores en esa escuela, ya que muchos docentes no poseen la conciencia de que la EA posibilita modificar intensamente las relaciones del hombre y el medio ambiente permitiendo una interacción y mutualidad, por lo que la escuela no puede quedar excluida de esta realidad, debiendo los docentes y gestores propiciar una mayor frecuencia del uso de temáticas dirigidas a la EA.

Palabras Clave: Docentes; Educación ambiental; Social-Ambiental

\section{INTRODUÇÃO}

Quando pensamos em educação estamos falando na maior ferramenta de transformação social, que existe em nosso planeta. Haja vista, que o caminho em que o homem estar conduzindo o planeta para uma demanda irreversível do uso dos recursos naturais. É preciso, que o homem quebre paradigmas, possibilitando assim, o convívio do "bicho homem" com a natureza, e para tal a educação tem um papel fundamental nesse processo de transformação, garantindo um futuro de preservação e de equilíbrio entre natureza e homem.

Nesse sentido, o presente artigo tem o enfoque na Educação Ambiental - EA voltandose para o ambiente escolar e no entorno da comunidade a partir das suas vivências. A pesquisa foi realizada no município de Sento Sé, situado na região do Baixo Médio São Francisco, na borda do Lago de Sobradinho, região norte do Estado da Bahia, Escola Núcleo Dois de Julho, de ensino fundamental II. Propõem investigar qual a freqüência do uso das temáticas da EA 
em convívio escolar, e se os professores desenvolvem projetos pedagógicos relacionados na área ambiental, uma vez que os conteúdos chegam aos alunos por meio do corpo pedagógico e professorado, oriundos da Secretaria de Educação. Diante do exposto a problemática da pesquisa é constituída pela seguinte pergunta: Analisar as contribuições das práticas pedagógicas dos professores na educação ambiental no nível fundamental II na Escola Núcleo Dois de Julho?

Com base na situação problema apresentada neste artigo, verifica-se a existência de uma necessidade de analisar se as temáticas do eixo da EA estão sendo utilizadas, sejam elas por meio da transversalidade ou por projetos interdisciplinares. Cabe salientar que as mesmas se asseguram em meio formal através da Lei Federal $n^{\circ}$ 9.795/99 e a Estadual $n^{\circ}$ 12.056/11. Assim, acreditando que as contribuições no processo de formação do sujeito homem socioambiental, poderá trazer soluções positivas para uma vivencia homem/meio ambiente mais equilibrado, voltada para a sobrevivência do planeta.

Nesse sentido o Objetivo Geral desta pesquisa é analisar as práticas dos professores no desenvolvimento do ensino da educação ambiental.

E os Objetivos Específicos são:

- Descrever o conhecimento dos professores junto a EA.

- Verificar como ocorre a formação inicial e continuada do professor frente à EA.

- Avaliar a frequência e o modo de como está sendo utilizado o eixo da EA no ensino fundamental II.

A metodologia utilizada nesta pesquisa é do tipo descritiva, não experimental, transversal e qualitativa.

No entanto, é de sublime importância assegurar o uso das temáticas da EA em espaço formal e não formal, em uma perspectiva de imbuir no sujeito em formação costumes, valores, ética associada à aquisição de atitudes socioambientalmente educada. Partindo dessa premissa, encontramos muitos referencias que apontam a importância da EA no processo de formação humana, sendo de suma importância que seja incorporado no ambiente escolar, visando assegurar a melhoraria da qualidade de vida como também ressaltando a existência dos recursos naturais, como fonte de vida, levando docentes e discentes a perceberem a importância para os dias atuais e as gerações futuras assegurando todas as formas de vida do planeta. 
Portanto, as considerações aqui fomentada, permitirão a reflexão crítica sobre a postura do docente e gestores, relacionada a metodologias de ensino da EA adotadas como prática pedagógico, procurando envolver tanto o discente quanto docentes e população, na árdua tarefa de preservação do ambiente, para então promover mudanças sociais e culturais, adequando-se as novas exigências e expectativas da realidade socioambiental.

\section{Referencial Teórico}

\section{Educações Ambiental em sua Contemporaneidade}

Há anos a EA vem se destacando no cenário educacional e mundial como um eixo complementar de fundamental importância para o processo de formação humana, onde a suas temáticas são consolidadas em meio educativo, promovendo uma perspectiva de mudanças de costumes do sujeito em pleno convívio com a natureza. Para tanto, essa nova tendência exige transformação no campo da educação, sendo preciso reavaliar teorias e reinventar estratégias e práticas pedagógicas que promovam uma maior integração entre natureza e homem. Desta forma, para a construção de um ensino contextualizado com a EA, exigem-se dos professores novas concepções de ensino aprendizagem, para atender ás expectativas e necessidades da nova demanda social, segundo Demo (2007, p.50) "não faria sentido educar a nova geração com estratégias velhas".

\section{Reflexão da Educação Ambiental nas Escolas}

A compreensão do ensino da EA vai proporcionar no ambiente escolar a possibilidade de uma interação entre Projeto Político Pedagógico (PPP) e o fazer pedagógico docentes no seu fazer pedagógico. Para tal a Lei n ${ }^{\circ} 9.795 / 99$ a nível Federal e a nível Estadual a Lei $n^{\circ}$ 12.056/2011 assegurada o ensino da EA, tornando-a algo de suma prioridade, pois "vivemos e respiramos por meio dos recursos naturais" que devem ser trabalhados na comunidade escolar e entorno da comunidade, mostrando sua importância quanto a preservação do meio ambiente, como forma de prevenir a nossa sobrevivência no planeta terra. 
Assim, possibilitando comparar as diversas realidades sociais no contexto da EA, proporcionando ao educando uma construção de parâmetros para melhorar a convivência do homem com a natureza.

\section{Capacitação dos Docentes}

Viver em uma sociedade capitalista com diversas dificuldades no meio econômico, social e cultural, obriga o docente amadurecer em relação ao processo de ensino, buscando novos conhecimentos, permitindo modificar sua postura mediante ao comodismo relacionado a sua formação. É visível a falta de incentivos por parte dos gestores em oferecer cursos de capacitação. E para quebrar paradigmas e adquirir novos conhecimentos o docente precisa investir por conta própria na sua capacitação, como forma de assegurar a construção de práticas metodológicas que atenta o processo de reflexão e formação do ser humano. Para Medina e Santos (1999, p.25), o conceito de EA é definido como:

A incorporação de critérios socioambientais, ecológicos, éticos e estéticos nos objetivos didáticos da educação. Pretende construir formas de pensar incluindo a compreensão da complexidade e das emergências e interrelações entre os diversos subsistemas que compõem a realidade.

No entanto, as mudanças na prática educativa, deve ser incorporada sem receio, deve ser vista com naturalidade, englobando-se a nova tendência de construção de conhecimento, possibilitando um processo crítico como a EA. Conforme Sato (2002, p.23) "a EA também está relacionada com a prática das tomadas de decisões e a ética que conduzem para a melhoria da qualidade de vida". Já para Carvalho $(1993$, p.40) quanto à prática EA temos o dever de construirmos "valores mais solidários a garantirmos a vida, para nossa e para aquelas que virão, não basta ser amigo das árvores e dos animais, é preciso criar práticas sociais efetivamente democráticas e solidárias na relação entre homens". Assim, os docentes devem estar sempre atentos ao surgimento das novas propostas educacionais, colocando em prática, com conformidade a legislação brasileira preconiza com relação à EA.

No entanto, a normatização detalhada acerca da institucionalização da EA em âmbito nacional, se efetiva somente com a publicação da Lei $n^{\circ}$ 9.795/99, que dispõe sobre a EA e institui o PNEA. Porém é de fundamental importância expor a definição para EA. Assim, segundo o Art. $1^{\circ}$. Entende-se por EA os processos por meio dos quais o individuo e a 
coletividade constroem valores sociais, conhecimentos, habilidades, atitudes e competências voltadas para a conservação do meio ambiente. E complementa atribuindo que é um bem de uso comum do povo, essencial à sadia qualidade de vida e sua sustentabilidade.

O Estado da Bahia através de Órgão Gestor da PEEA, coordenado pela Secretaria de Meio Ambiente e da Educação teve a preocupação de criar e apresentar o Programa de EA do Estado da Bahia o PEA-BA, embasado pela Lei $\mathrm{n}^{\circ}$ 12.056/2011 através de um processo articulado a consulta pública a qual reuniu aproximadamente 5.000 pessoas em 26 seminários territoriais, sendo o momento precursor resultante da sistematização dos conteúdos debatidos nas consultas. É importante ressaltar que houve uma grande sintonia entre a Lei e o programa de EA, que destacaram a Comunicação, a Transversalização e a Avaliação como eixos estruturante.

\section{Lei de Diretrizes e Bases da Educação - LDB, Parâmetros Curriculares Nacionais - PCN's e Currículo}

Em especial a Lei de Diretrizes e Bases da Educação Nacional - LDB nº 9.394/96, em seu artigo 32 que prevê o ensino fundamental gratuito nas escolas públicas, sendo obrigatório, possuindo como objetivo a formação básica do cidadão, e destacando no inciso II que essa educação deverá ser pautada na compreensão do ambiente natural e social, do sistema político, da tecnologia, das artes e dos valores em que se fundamentam a sociedade.

Em detrimento da necessidade de estarem sempre a acompanhar as mudanças educacionais, os docentes devem se permitir a inovações, pois, uma coisa é saber ser critico para melhorar, outra coisa é participar de novas buscas sem resistir a novos perfis de profissionalização, sem perder tempo a resistências sem significâncias. Uma vez que, esses docentes não participam de nenhuma formação continuada, não se permitem familiarizarem com as novas tendências educacionais somente promoverá um estacionamento desse profissional o tornando ultrapassado contribuindo pouco para o processo de formação cidadã.

Assim sendo, a definição de parâmetros no campo curricular visando orientar ações educativas mais eficientes já estava prevista inclusive no Plano Decenal de Educação (1993 2003) e na própria Constituição de 1988, que já insinuava essa estratégia. Assim, organizando seus conteúdos de forma estratégica e em volumes de cores diferente os parâmetros curriculares são fonte inspiradora para reforma educacional promovida na Espanha em 1990. 
No que se refere à concretização propriamente dita dos PCNs, na escola foi uma organização de 04 níveis distintos ficando assim organizado: um primeiro nível tido como referencial para a elaboração das políticas do MEC, subsidiando a elaboração ou revisão curricular dos Estados e Municípios; um segundo nível que diz respeito à adaptação do mesmo como parâmetro para a elaboração das propostas curriculares das Secretárias de Educação dos Estados e Municípios; um terceiro concernente ao ajuste das propostas curriculares de cada instituição escolar, e por fim um quarto nível de concretização que se refere à programação das atividades de ensino e aprendizagem em cada sala de aula. Sancho (1998, p.16) salienta que:

Infelizmente, essa nova proposta curricular não tenha vindo acompanhada de uma necessária reforma social, política, cultural, e econômica que enfrente os problemas básicos que perpetuam a situação do sistema educativo público. Assim, reitera afirmando que em momento algum podemos ignorar o óbvio. A escola não educa sozinha. Se não existir um pacto social com as demais instituições sociais e inclusive a familiar, somadas às reformas necessárias ao seu desenvolvimento, não será possível formar cidadão nos valores propostos pelos PCNs, sobretudo em relação à transversalidade ambiental.

No entanto, vale ressalta a importância que houve na preparação de todo o sistema educacional, voltada para as novas vivencias que se iriam enfrentar, mediante a toda essa preparação para 'a incorporação da EA' pelos docentes nas aulas devem ser frequentes, fazendo parte da rotina diária, para isso os docentes precisam de conhecimento, que virá mediante o processo de qualificação. Logo, o mesmo refletirá sobre sua prática e se permitirá a mudanças, não tendo medo de experimentar e errar enquanto aprende. Assim, poderão proporcionar um fazer pedagógico condizente com as necessidades atuais dos alunos, que constantemente sofrem influências de outras instituições sociais, que caminham a seu passo para novas inovações.

\section{METODOLOGIA}

\section{Justificativa da metodologia}


Visando responder aos objetivos elencados nesse artigo, foi realizada uma pesquisa aplicada, uma vez que possui a finalidade de gerar conhecimentos para aplicação de uma prática dirigida a problemas específicos, que é motivada pela necessidade e curiosidade do professor, fortalecendo sua prática, através da utilização das temáticas da EA de forma formal. Assim, proporcionando de forma direta ou indiretamente um campo mais frutífero de aprendizagem em meio educacional.

Sendo também qualitativa, haja vista que se preocupa em analisar e interpretar aspectos mais profundos, descrevendo a complexidade do comportamento humano. Assim, Segundo Lakatos e Marconi (2006, p.269), "fornece análise mais detalhada sobre as investigações, hábitos, atitudes, tendências de comportamento, etc.”. Dessa forma, a pesquisa se desenvolveu sobre o cunho descritivo, pois visa descrever as características de determinada população (docentes e gestores da Escola Núcleo Dois de Julho, de ensino fundamental II em Sento-Sé- Bahia), utilizando como levantamento o questionário, que segundo Gil (2002, p.116) consiste em traduzir os objetivos específicos da pesquisa em itens bem redigidos. Sendo ratificado por Couto (2013, p.42) quando diz: "uma pesquisa de natureza qualitativa pode-se utilizar o questionário, mas, normalmente, este possui questões abertas para que o entrevistado possa descrever, explicar, relatar, etc., sua ideia sobre o tema em estudo". Em outras palavras o entrevistado precisar estar bem à vontade e seguro do que está relatando. Para Sampieri, Collado e Lucio (2013, p. 104), os estudos descritivos buscam especificar as propriedades, as características e os perfis de pessoas, grupos, comunidades, processos, objetos ou qualquer outro fenômeno que se submeta a uma analise.

\section{Desenho, tipo e enfoque da pesquisa.}

Portanto, mediante o modelo de pesquisa possibilita que seja traçado um plano de ação, ou seja, um andar que possibilite a coleta de subsídios que se torna tão necessárias no desenvolvimento prático e concreto da pesquisa, possibilitando assim que os seus objetivos sejam conseguidos e que as questões pertinentes sejam respondidas. Segundo Lakatos e Marconi (2007, p.157), "para que as fases da pesquisa se processem normalmente, tudo deve ser bem estudado e planejado, inclusive a obtenção de recursos materiais, humanos e de tempo". Neste sentido a pesquisa propõe analisar de forma descritiva o conhecimento e a prática dos professores com relação a EA, quanto ao uso de suas temáticas no processo de 
formação do sujeito homem socioambientalmente educado na Escola Núcleo Dois de Julho no Distrito de Riacho dos Paes Sento Sé/Bahia.

No período da coleta de dados serão observados e refletidos como as temáticas da EA foram abordadas, se há projetos didáticos voltados para a referida área e se a escola desenvolve seus conteúdos em uma perspectiva socioambiental. Assim, ter parâmetros se esse eixo complementar da educação básica está sendo utilizado como instrumento pedagógico e realmente é capaz de melhora o rendimento dos alunos. Para isso, serão analisados os objetivos pretendidos, comparando-os e interpretando sem manipulação ou intervenção, porem com o intuito de analisar as influencias da EA na prática pedagógica do professor.

Como a presente investigação é do tipo descritiva e segue o enfoque qualitativo, segundo Sampieri, Collado e Lucio (2013, p.376) “compreender a perspectiva dos participantes (indivíduos ou grupos pequenos de pessoas que serão pesquisados) sobre os fenômenos que os rodeiam, aprofundar em suas experiências". Assim, foi escolhido como população os 11 professores e os 03 gestores do ensino fundamental II da Escola Núcleo Dois de Julho.

\section{Populações participantes}

Mediante essas informações o presente instrumento foi aplicado para uma população de 11 professores e 03 gestores que lecionam em uma escola públicas municipal, que segundo Lakatos e Marconi (2008, p.38), o "pesquisador está interessado na opinião (ação, intenção etc.) de determinados elementos da população, mas não representativos dela”. Essa população a ser investigada precisa ter compreensão do seu papel no campo da pesquisa, pois ele (a) é o alvo a ser estudado. Para Sampieri, Collado e Lucio (2013, p.193) população é um "conjunto de todos os casos que preenchem uma série de especificações". Tal conjunto de especificações precisam ser coerente e precisos para o desenrolar da pesquisa. Por fim, os questionários foram analisados refletindo, estabelecendo parâmetros embasados nos objetivos, teorias e legislação vigente sobre o uso das temáticas da EA no ambiente escolar, a fim de elaborar as considerações propositivas e recomendações.

\section{Análise, Discussão Dos Dados E Resultados}


O universo da pesquisa se consolidou com uma amostra composta por 11 professores e 03 gestores, representando a Escola Núcleo Dois de Julho do Distrito de Riacho dos Paes cidade de Sento Sé Bahia.

Os docentes e gestores que participaram da pesquisa possuem no mínimo 2 a 25 anos lecionando na rede municipal de Sento Sé, e os gestores sendo dois por indicação política, porém os mesmos são professores da referida escola e a coordenadora pedagógica comunga da mesma situação dos demais docentes. Assim, como concursados no ensino fundamental, ministrando aula atualmente na Escola Núcleo Dois no Ensino Fundamental II, sendo que apenas 04 dos docentes pesquisados são formados nas áreas as quais ministram aulas no ensino fundamental II, enquanto 07 docentes não tem área especifico do conhecimento, mas todos tem nível superior e desenvolvem trabalho como regime de aula complementar de acordo com um Termo de Ajuste de Conduta - TAC, em comunhão com a Lei n ${ }^{\circ} 104 / 2005$, o qual é previsto no Plano de Carreira do servidor municipal, que formalizou um acordo com Gestão, Ministério Público e Sindicatos dos Servidores.

A maioria dos docentes possui a faixa etária entre 32 a 52 anos de idade. Assim, abaixo apresentaremos as questões específicas sobre quanto à familiaridade dos docentes em relação ao uso das temáticas ambientais nas salas de aula e extraclasse, analisando as respostas fornecidas pelos professores e também o grau de conhecimento dos gestores da referida escola já anteriormente citada.

O eixo complementar da EA se faz obrigatório a nível nacional em toda educação básica, uma vez que, reconhecido por força maior através da Lei n ${ }^{\circ}$ 9.795/99 de 27 de Abril, do referido ano, sendo incorporada à Lei no 9.394/96 e em 2011 regulamentada a nível Estadual formada através de audiência pública criando a Lei ${ }^{\circ}$ 12.056/2011 consolidando ainda mais o obrigatoriedade do uso do eixo no processo de formação humanamente socioambiental. Entende-se que o espaço escolar como um todo é um ambiente formador de sujeito critico participativo reflexivo consciente do seu espaço em plena convivência com o meio ambiente e a sociedade e como sujeito protagonista de suas ações e vivencias.

Assim sendo, mais do que nunca a escola necessita estar envolvida em uma perspectiva ambiental com o intuito de mediar os conhecimentos desses cidadãos que estão sendo "formados". Para isso, a mesma deve oportunizar o contato frequente do uso das temáticas tanto por sequencia didática quanto por meio de projeto pedagógico que envolva todo o panorama da EA na escola, em sala de aula e que esse envolvimento de aluno e 
comunidade escolar possibilite que as metodologias escolares perpassem os seus muros e envolva toda a comunidade.

Desse modo, é o professor no ambiente escolar que realizará a tarefa de mediar esses conhecimentos e inserção da EA, através de sua prática pedagógica que alie o educar e o cuidar, "formando" integralmente esse indivíduo para participar ativamente na sociedade da informação e comunicação de forma mais socioambientalmente educado.

Logo, segundo Anjos (2008, p.130) a educação ambiental:

Reveste-se a cada dia de maior importância, tornando vital, que, não só as escolas, mas também aos movimentos populares e ambientais que mergulhem na complexidade desses problemas, procurando aumentar a reflexão de forma a influir no nível de conscientização de todos os cidadãos que sensibilizam-se com esta problemática. Acredita-se que, a partir desse comportamento estaremos mais atentos aos problemas sociais e a partir daí seremos capazes de propor formas de desenvolvimento que estejam ligados à melhoria da qualidade de vida de todo ser.

Nesse sentido o professor precisa está sempre revendo o seu papel diante da sociedade, onde fica perceptivo a necessidade de estar em plena ação de busca de conhecimento, estando aberto para resignificando do seu papel mediante a essa sociedade contemporânea. Segundo Reigota $(2015$, p.70) a "escola contemporânea se depara com uma série de demandas, muitas vezes, indissolúvel, que a obrigam a repensar o seu papel na sociedade, arcando com o peso de ter que ser a salvadora do mundo".

Buscando então, conhecer o grau de familiaridade dos gestores da presente instituição frente ao eixo da EA, foi questionado se ambos consideram ter conhecimentos suficientes para direcionar os docentes em uma prática socioambiental e assim, classificarem o grau de familiaridade (seu manuseio) frente ao eixo da EA.

De acordo com as respostas dos gestores, o nível de conhecimento dos mesmos frente ao eixo da EA, é considerados básico, uma vez que, os mesmos não tem proximidade com temáticas, mesmo que uma hora ou outra, desenvolvam projetos ou sequência didáticas referentes ao eixo, onde demonstram não dominar metodologicamente de forma ampla, conhecimento necessários para desenvolver de forma satisfatória uma junção interdisciplinar e transversal entre os saberes voltados para a EA. Salientam ainda, que nunca receberam nem um tipo de formação para a área da EA. 
Em contrapartida os docentes da referida escola em conformidade com o mesmo questionamento, foram abordados quanto ao conhecimento da EA, os mesmos dizem saber conhecer tanto o conceito da EA quanto o de Sustentabilidade, onde confrontados com relação aos conhecimentos das Leis que asseguram a EA a nível Federal e Estadual Lei no 9.795/99 e a Lei ${ }^{\circ}$ 12.056/11, a grande maioria dos professores descreveram não conhecer as leis.

Cabe salientar, que desenvolver o uso do eixo EA, tem por objetivo consolidar se por meio do conhecimento pedagógico dos docentes na referida área. Caso os docentes não tenham uma formação voltadas para EA, existe uma grande possibilidade de não desenvolverem a temáticas da EA de forma que venha possibilitar um ensino aprendizado na referida área e, ainda pior seria, a não valorização dos bens comuns a todos que são os recursos naturais, disseminando uma prática desconexa com a realidade, indo na contramão da sustentabilidade e da formação de sujeitos moralmente éticos e socioambientalmente educados. Portanto, em uma perspectiva socioambiental às práticas dos docentes se tornará uma ação capenga, que resultará em pouco benefício no processo de formação do sujeito homem socioambientalmente educado. De acordo com Segura (2001, p.22) a escola é:

Um espaço de trabalho fundamental para iluminar o sentido da luta ambiental e fortalecer as bases da formação para a cidadania, apesar de carregar consigo o peso de uma estrutura desgastada e pouco aberta às reflexões relativas à dinâmica socioambiental.

Para tanto é importante que os docentes em processo de formação, deparem com estudos voltados para o ensino da EA, para que posteriormente à sua formação possa contribuir de forma mais assídua com o processo de formação do sujeito ético, político e social.

Verificando como ocorre a formação dos professores e gestores junto a EA, foi perguntado a ambos se eles sabem como AE se faz presente no currículo, se conhecem as leis que regulamentam e se os mesmos têm formação na área? Cabe salientar que tanto os professores quanto os diretores, nunca receberam nem um tipo de formação voltada para a educação ambiental. Entre os gestores, somente a gestora pedagógica participou de um momento de leitura, mas outras colegas de profissão logo quando a Lei $n^{\circ}$ 9.795/99 foi colocada em prática em 2002 promulgado pelo decreto $n^{\circ} 4.281$. Dessa forma é perceptível uma vulnerabilidade no processo de formação docente e consequentemente na prática do 
professor como também dos diretores. Quanto a se fazer presente no currículo, somente a coordenadora pedagógica sobe informar que é de forma transversal em uma perspectiva interdisciplinar. Quanto ao conhecer das leis que regulamentam a EA, na grande maioria não souberam responder.

Ao avaliar a frequência e o modo de como estava sendo utilizando o eixo da EA, foi perguntado tanto aos gestores como professores, se em comunhão de sugestão por parte da direção e desenvolvimento por parte dos professores, se existe a utilização de temáticas ambientais voltadas para uma educação socioambiental? O que ficou evidenciado é que no ano de 2017, a escola pesquisada até o momento da pesquisa, não havia desenvolvido nem um projeto se quer, o que complica ainda mais o processo ensino aprendizagem. Processo esse que precisa ser norteado, uma vez que o município referido desenvolvem suas ações educacionais por meio da metodologia de projetos.

No entanto, mesmo diante de uma desorganização pedagógica escolar, em análise realizada nos diários de classes, evidenciou-se que algumas disciplinas principalmente as que respiram em sua base conteúdo das temáticas da EA, desenvolveram temáticas que abrangeram para formação humanamente socioambiental. Cabe salientar ainda que em outras circunstancias foi sugerido de forma superficial pelos gestores, tanto pedagógico quanto administrativos, que desenvolvessem na semana do meio ambiente uma sequência didática para as temáticas ambientais, mas por falta de gerencia poucas disciplinas realizaram. Ressaltam ainda que quando a escola elabora e desenvolve projetos para a EA, todos se envolvem da melhor maneira possível, disseminando atividade de cunho grupal como: caminhada ecológica, mutirão de limpezas, visitação ao rio, panfletagens etc.

\section{CONCLUSÕES E RECOMENDAÇÕES}

Ao final da análise aqui empreendida e embasada nas respostas obtidas dos docentes e gestores é nitidamente visível que muito se fala da necessidade de buscar novas metodologia de ensino, que possibilitem um aprendizado significativo, que torne os nossos educandos cidadão consciente e protagonistas de sua realidade, com competência de conhecimento social e em especial a defesa do meio ambiente sustentável.

Com relação ao primeiro objetivo que é: Descrever o conhecimento dos professores junto a EA: Fica evidenciado que é necessária a interação e apropriação de novos 
conhecimentos e pesquisas na área das temáticas ambientais por parte dos professores, como também dos gestores, ou seja, como um todo, para que mediante a aquisição de novos conhecimentos na referida área, possibilite que todos se envolvam no processo a realizarem um novo modelo de ensino aprendizagem, envolvendo o sujeito em formação para a aquisição de novas habilidades e competências para um novo aprender, permitindo assim, articulação e a interação entre as diversas áreas do conhecimento, possibilitando a escola uma construção e reconstrução dos informação, voltadas sempre para o presente, olhando para o futuro e caminhando lado a lado com os problemas e soluções socioambientais.

Em relação ao segundo objetivo específico: Verificar como ocorre a formação inicial e continuada dos professores junto a EA. Conclui-se que embora os professores da referida escola na sua maioria não tenham conheciemnto aprofundado com relação a EA, pois, nunca fizeram nem uma formação na área, ficou evidenciado que quando desenvolvem as temáticas da referida área, as desenvolvem por meio do senso comum e que as ferramentas pedagógicas utilizadas, seja por meio de sequências didáticas ou por meio de projetos didáticos pedagógicos, conseguem promover uma educação socioambientalmente educada.

Assim sendo, torna-se imprescindível a inserção frequente das temáticas da EA pelos docentes na Escola Núcleo Dois de Julho do ensino fundamental II do município de Sento Sé/Ba, sendo utilizadas de maneira consciente em sala de aula e fora dela, onde a gestão escolar possibilite e promova a interação das temáticas do eixo da EA, e que as tornem ferramenta de aquisição de conhecimento, para atender as necessidades da comunidade com relação a EA. Para Gil (2008, p 32.), “O professor é a figura responsável por organizar o ambiente despertador da motivação do aluno para a aprendizagem de algo". Assim é importante que os professores busquem capacitação para saber manusear na sua prática pedagógica diária a educacionais o eixo da EA.

Em relação ao terceiro objetivo específico: Avaliar a frequência e o modo de como está sendo utilizado o eixo da EA no ensino fundamental. Conclui-se que no ano de 2017, a Escola Núcleo Dois de Julho encontrava-se pedagogicamente desorganizada, uma vez que nesse ano em curso até a data da pesquisa entre Outubro e Novembro, até então não havia desenvolvido nem um projeto pedagógico para temática da EA e nem uma outra temática educacional. Cabe salientar, que com relação à EA, o que foi desenvolvido foi uma sequência didática oriunda da sugestão por parte da direção administrativa e pedagógica na semana do 
meio ambiente, configurando-se de forma muito individualizada o fazer pedagógico dos professores com relação às disciplinas.

Embora essa fragilidade no desenvolver das ações pedagógicas da escola, as disciplinas as quais desenvolveram a sequência didáticas, as fizeram com êxito, promovendo assim, uma reflexão sobre a importância do meio ambiente para a vida no planeta.

Nesse sentido, é importante salientar que uma unidade de ensino não pode se dar ao luxo de desenvolver suas atividades de forma desorganizada, pois um andar nessa perspectiva não possibilita uma formação coerente para nenhum cidadão.

No entanto tanto gestores como professores e Secretaria de Educação precisam ter a percepção que suas ações mal direcionadas poderão promover mudanças relacionadas ao ambiente escolar. Assim é de sublime importância que se reorganize para um novo andar com interações entre recursos tradicionais e inovadores, unindo teoria e prática como forma de inserção ou resgate da EA no Projeto Político Pedagógico, estabelecendo critérios, regras e reflexões pertinentes no contexto escolar, transformando assim, as práticas pedagógicas no ensino aprendizagem dos seus educandos.

\section{REFERÊNCIAS}

Anjos, M. B. (2008). Educação ambiental e interdisciplinaridade. São Paulo: Libra Três.

Secretaria de Meio Ambiente. (2013). Programa de educação ambiental do Estado da Bahia. Salvador: EGBA.

Secretaria da Educação. (1996). Estabelece as diretrizes e bases da educação nacional. Brasília. Ministério da Educação.

Moura, I. C. (1993). Educação, meio ambiente e ação política: Desenvolvimento e meio ambiente. Rio de Janeiro: Ibase.

Souza M. E. (2013). Metodologia da pesquisa em educação II .Ilhéus: Editus.

Demo, P. (2007). O porvir: desafio das linguagens do séc. XXI. Curitiba: IBPEX.

Gil, A. C. (2002). Como elaborar projetos de pesquisa. São Paulo: Atlas.

Gil, A. C. (2008). Métodos e técnicas de pesquisa social. São Paulo: Atlas.

Lakatos, E. M., e Marconi, M. A. (2006). Fundamentos de Metodologia cientifica. São Paulo: Atlas. 
Lakatos, E. M., e Marconi, M. A. (2007). Fundamentos de Metodologia cientifica. São Paulo: Atlas.

Lakatos, E. M., e Marconi, M. A. (2008). Técnicas de Pesquisa: planejamento e execução de pesquisa, amostragens e técnicas de pesquisa, elaboração, análise e interpretação de dados. São Paulo: Atlas.

Medina, N. M., e Santos, E. C. (1999). Educação Ambiental. Uma metodologia participativa de formação. Petrópolis: Vozes

Ministério do Meio Ambiente. (2005). Programa nacional de educação ambiental. Brasília.

Reigota, M. (2015). Educação ambiental e práticas pedagógicas cotidianas. São Paulo: Intermeios.

Sancho, J. (1998). O currículo e os Temas Transversais: Misturar água e azeite ou procurar uma nova "solução"? Rio Grande do Sul: Artes Médicas.

Sato, M.(2002). Educação ambiental. São Carlos: Rima.

Segura, D. S. B. (2001). Educação ambiental na escola pública. São Paulo: Fapesp.

Hernández Sampieri, R., Collado Fernández, C., e Baptista Lucio, M. (2013). Metodologia de la Investigación. Porto Alegre: Penso 